\title{
Desigualdade de renda e mercado de trabalho na metrópole e no interior do Rio de Janeiro ${ }^{1}$
}

\author{
Valéria Pero \\ Adriana Fontes \\ Camila Ferraz $^{2}$
}

\begin{abstract}
RESUMO
O Estado do Rio de Janeiro tem avançado menos que a média brasileira e que seus vizinhos do Sudeste em vários indicadores socioeconômicos, mas principalmente quanto à desigualdade de renda. Este estudo busca contribuir para o entendimento desse fato, analisando primeiramente o desenvolvimento da região metropolitana em relação às outras regiões metropolitanas do país, e em seguida de forma territorializada entre capital, resto da região metropolitana (periferia) e área não metropolitana do Estado (interior). Assim como o Estado, a evolução da Região Metropolitana do Rio de Janeiro (RMRJ) tem sido aquém de outras metrópoles e do Brasil em termos de desigualdade, pobreza e informalidade no mercado de trabalho. A RMRJ tem freado os avanços do Estado na redução da desigualdade, sobretudo pelo desempenho da capital, que registra maior Coeficiente de Gini e diferencial salarial para níveis superiores de escolaridade elevados e crescentes. Outra possível explicação para a redução mais lenta da desigualdade na RMRJ reside na distância entre os rendimentos dos empregados em micro e pequenas empresas e em médias e grandes empresas, maior na RMRJ do que na média brasileira ou da Região Metropolitana de São Paulo.
\end{abstract}

Palavras-chave: trabalho; desigualdade de renda; Rio de Janeiro

\begin{abstract}
The socioeconomic indicators of the State of Rio de Janeiro have been improving at a slower rate in comparison to the Brazilian average and to other Southeastern States, specially in terms of income inequality. This article contributes to the understanding of this fact, analyzes the development of the metropolitan area compared to other metropolitan areas, and then considers the territorial differences between the capital, the rest of the metropolitan area (periphery) and non metropolitan areas in the state (countryside). Such as the state, the evolution of the Metropolitan Region of Rio de Janeiro (RMRJ) has been lagging behind in comparison to other cities and Brazil in terms of inequality, poverty and informality in the labor market. The RMRJ has slowed the progress of the state in reducing inequality, mainly

\footnotetext{
${ }^{1}$ Este artigo tem como base o Estudo Estratégico n. 5 do Observatório de Micro e Pequenas Empresas do Estado do Rio de Janeiro do Sebrae/RJ e IETS.

${ }^{2}$ Valéria Pero: Professora do Instituto de Economia da UFRJ. valuciapero@ gmail.com Adriana Fontes:

Pesquisadora do IETS e consultora da Macroplan. Camila Ferraz: Técnica do Instituto Pereira Passos.
} 
driven by the capital, showing the highest Gini coefficient and wage gap between high and average level of schooling. Another possible explanation for the slower reduction of inequality in RMRJ lies in the wage gap between employees in micro and small enterprises and medium and large companies, which in RMRJ is higher than the Brazilian average or the Metropolitan Region of Sao Paulo.

Keywords: labor market; income inequality; Rio de Janeiro; metropolitan region

\section{Introdução}

Como em todas as metrópoles do Brasil (e do mundo) a concentração urbana, econômica e populacional é acompanhada de inúmeros desafios no âmbito da pobreza, da desigualdade de renda, do acesso ao trabalho e ao transporte público de qualidade. Estas pressões tornam as metrópoles mais complexas assim como a busca de soluções para seus problemas. O Estado do Rio de Janeiro (ERJ) se destaca neste cenário, uma vez que é o estado mais metropolitano do Brasil.

A Região Metropolitana do Rio de Janeiro (RMRJ) concentra $74 \%$ da população, responde por aproximadamente $3 / 4$ da economia do ERJ, 68\% das empresas e $75 \%$ do emprego de todo o estado. Mas a concentração não é apenas econômica. A RMRJ abriga, sozinha, 74\% da pobreza do ERJ, sendo que $44 \%$ do número de pobres estão em suas áreas periféricas (exceto a capital).

Se a "encrenca" é metropolitana ${ }^{3}$ tamanha sua complexidade, pode-se dizer que no caso do Rio de Janeiro os desafios ganham uma proporção ainda maior. Assim como a trajetória do ERJ, a RMRJ, quando comparada às demais RM brasileiras, vai aos poucos perdendo a sua posição em função de um ritmo mais lento na redução da desigualdade de renda.

\footnotetext{
${ }^{3}$ Tema abordado por Urani (2008), segundo o qual os problemas socioeconômicos das metrópoles do Rio de Janeiro e de São Paulo são um importante limite do desenvolvimento brasileiro, os quais chamou de "encrenca metropolitana". Problemas advindos de um processo de globalização e realocação das atividades econômicas na entrada do segundo milênio que levou à "perda de vocação dos subúrbios metropolitanos, desemprego, crescente polarização, novas formas de segregação social e ruptura de vínculo de solidariedade social". Para mais detalhes: http://www.iets.org.br/biblioteca/RAP_boletim2.pdf. out. Para outros pontos e contrapontos sobre a decadência da Região Metropolitana do Rio de Janeiro ver Osorio (2011) e Sobral (2013).
} 
Esta evidência torna ainda mais complexa a busca por soluções dentro do ERJ e seus recortes territoriais (RMRJ, capital, RMRJ sem capital e área não metropolitana), ${ }^{4}$ tão díspares em termos de desenvolvimento. Compreender estas especificidades territoriais é fundamental para sair da inércia concentradora de recursos e do desenvolvimento aquém dos demais estados e do Brasil. ${ }^{5}$

Nesse contexto, o presente artigo analisa a evolução da desigualdade de renda e do mercado de trabalho na RMRJ, considerando o recorte territorial entre capital, região metropolitana sem a capital (periferia) e área não metropolitana do estado (interior). Com isso, busca-se compreender o padrão e as especificidades do desenvolvimento socioeconômico do Rio de Janeiro. Para tanto, serão utilizados dados da Pesquisa Nacional por Amostra de Domicílios (PNAD/IBGE), da Pesquisa Mensal do Emprego (PME/IBGE) e da Relação Anual de Informações Anuais (RAIS/MTE) de 2001 a 2011, que permitem identificar os pontos de convergência e divergência entre esses recortes territoriais.

Assim sendo, o artigo apresenta três seções, além desta Introdução. A primeira seção analisa a evolução dos indicadores da Região Metropolitana do Rio de Janeiro em relação à média brasileira e à Região Metropolitana de São Paulo (RMSP). A segunda seção busca verificar o quão distinta tem sido a evolução dos indicadores socioeconômicos na capital, no resto da região metropolitana e na área não metropolitana do Rio de Janeiro. Finalmente, apresentam-se as principais conclusões do artigo.

\section{A questão metropolitana}

\subsection{Renda, pobreza e desigualdade}

A RMRJ tem o segundo maior PIB entre as metrópoles brasileiras, ficando atrás somente de São Paulo. A evolução da economia entre 2002 e 2010 revela um desempenho inferior da RMRJ. A taxa média de crescimento anual na RMRJ foi de 2,0\%, inferior à da RMSP $(4,1 \%)$ e à da média brasileira $(4,6 \%)$. Além disso, o crescimento da RMRJ foi muito inferior ao do estado $(3,5 \%)$, fato que não ocorreu em São Paulo.

\footnotetext{
${ }^{4}$ Esse recorte territorial do estado também pode ser visto a partir da nomenclatura de capital, periferia (municípios que compõem a região metropolitana, excluindo a capital) e interior (municípios da área não metropolitana). No Rio de Janeiro, são 18 municípios na periferia da região metropolitana e 73 municípios no interior.

${ }^{5}$ Para uma análise sobre evolução recente do desenvolvimento do Estado do Rio de Janeiro ver Fontes et al. (2013).
} 
O Rio, medido pela sua renda per capita em 2011, é o quarto estado mais rico do Brasil, ficando atrás de Distrito Federal, São Paulo e Santa Catarina. Já a RMRJ possui uma renda per capita inferior às regiões metropolitanas do Sul e Sudeste, embora acima da média brasileira. Isso se deve ao crescimento menor da renda domiciliar per capita nas Metrópoles do Rio de Janeiro e de São Paulo (18,5\% e 16,2\% respectivamente) do que no Brasil (32,5\%), entre 2002 e 2011. Mais recentemente, entre 2008 e 2011, a expansão da renda per capita vem desacelerando na RMRJ (2,6\%), enquanto na RMSP houve alta de 10,8\%.

A distribuição da renda per capita na RMRJ é a segunda mais desigual das nove RMs brasileiras. O Coeficiente de Gini é de 0,54, superior ao do Brasil $(0,53)$ e inferior apenas ao da Região Metropolitana de Salvador.

A trajetória das metrópoles na redução da desigualdade revela que a RMRJ avança menos, de modo a ampliar sua distância em relação ao Brasil e à RMSP, conforme pode ser visto no Gráfico 1. Entre 2001 e 2011, a queda da desigualdade da RMRJ foi de 5,1\%, menos da metade da queda da desigualdade da RMSP $(10,8 \%)$ e brasileira $(11,1 \%)$. Entre as nove RMs cobertas pela PNAD, a RMRJ foi a que apresentou menor redução da desigualdade, exercendo forte influência sobre o ritmo mais lento de diminuição das desigualdades no Estado do Rio de Janeiro.

\section{Gráfico 1}

Coeficiente de Gini: 2001 a 2011

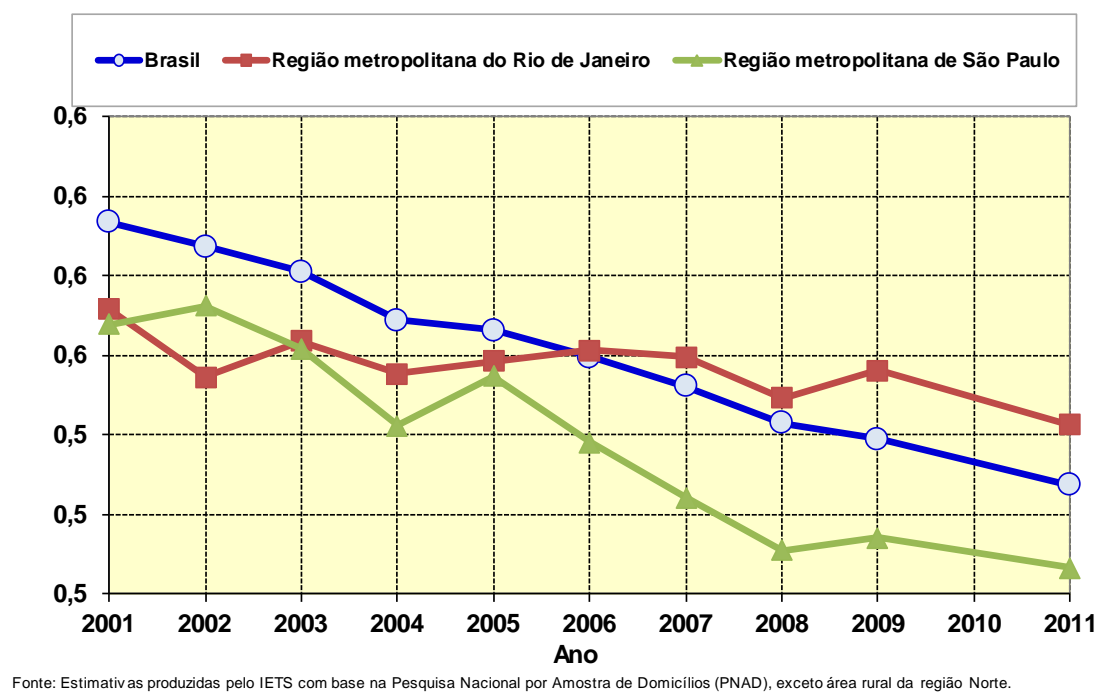

A combinação de desaceleração do crescimento da renda per capita com avanços lentos na redução da desigualdade resultou na diminuição mais tímida do número de pobres 
na metrópole fluminense. ${ }^{6}$ A redução do percentual de pobres na RMRJ foi de $40 \%$, entre 2001 e 2011, inferior à brasileira $(47 \%)$ e à da RMSP (49\%). No período mais recente de 2009 a 2011, como pode ser visto no Gráfico 2, a RMRJ mostrou estabilidade nesse percentual, em 16,4\%, enquanto a metrópole paulista reduziu o percentual de $15,9 \%$ para $12 \%$.

\section{Gráfico 2}

\section{Porcentagem de pobres: 2001 a 2011}

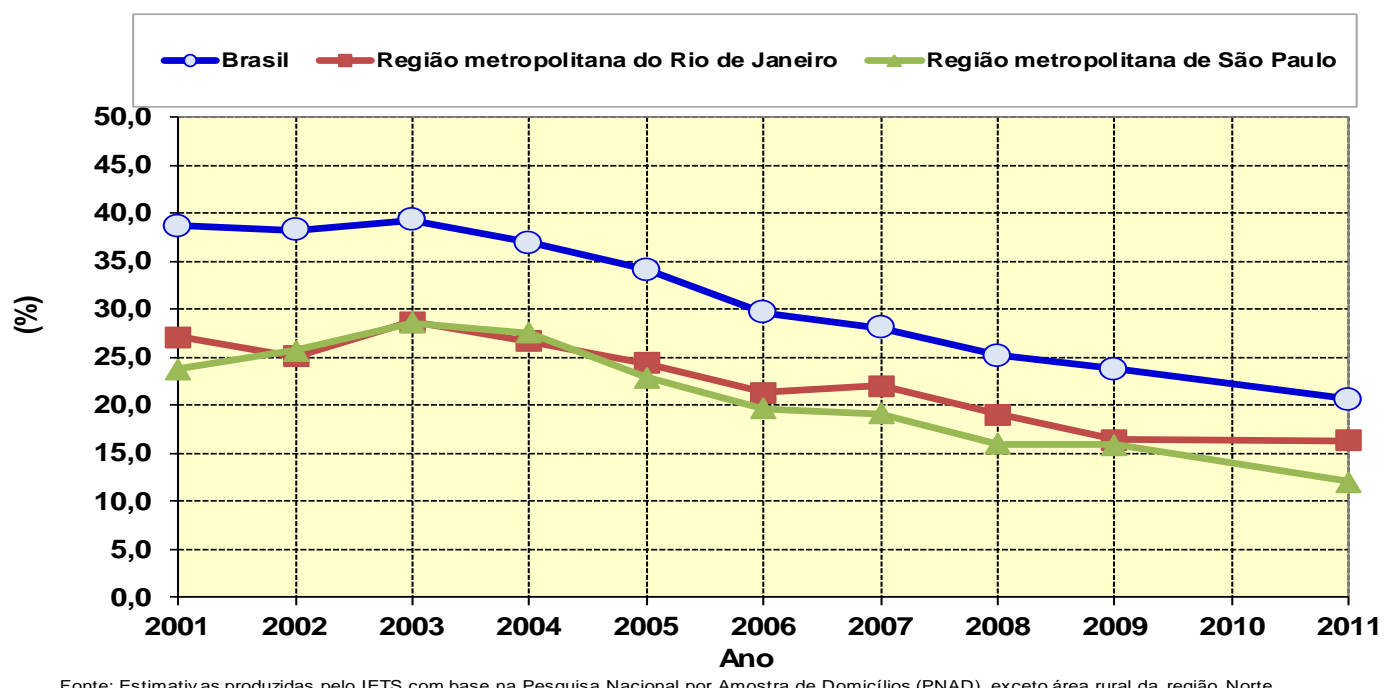

\subsection{Mercado de trabalho}

De acordo com Barros e Pero (2010), a diferença no combate à pobreza do Rio de Janeiro em relação a estados mais bem-sucedidos, como Santa Catarina, está relacionada, principalmente, ao acesso ao trabalho. Neste sentido, analisamos os principais indicadores para avaliar as condições de trabalho e renda na RMRJ relativamente a São Paulo e à média brasileira. $^{7}$

A RMRJ está em posição mais favorável em alguns indicadores. Esse é o caso da taxa de desocupação, inferior à do Brasil e à da Região Metropolitana de São Paulo. Com uma taxa de 4,8\% na média do primeiro trimestre de 2013, a RMRJ tem o terceiro menor desemprego entre as seis RMs da PME, superior apenas à de Porto Alegre e à de Belo Horizonte. Porém a

\footnotetext{
${ }^{6}$ As linhas de pobreza utilizadas são regionalizadas: RMRJ (R \$ 252); área não metropolitana urbana do Rio de Janeiro (R\$ 214); área não metropolitana do Rio de Janeiro (R\$ 192); RMSP (R\$ 253); área não metropolitana urbana de São Paulo (R \$ 224); área não metropolitana rural de São Paulo (R \$ 183).

${ }^{7}$ Vale destacar também que $2 / 3$ da queda da desigualdade recente é explicada pela diminuição da desigualdade na renda do trabalho, conforme pode ser visto em Barros, Foguel e Ulyssea (2006).
} 
RMRJ tinha a menor taxa de desemprego das regiões metropolitanas da PME e teve a menor redução do desemprego da última década.

Vale ressaltar que esse desempenho é influenciado pela menor pressão da oferta de trabalho, característica peculiar do Rio de Janeiro. A taxa de participação ${ }^{8}$ da metrópole fluminense, de 54,9\%, é a segunda menor dentre as 6 RMs consideradas pela PME/IBGE, abaixo, inclusive, da taxa de participação brasileira $(57,2 \%){ }^{9}$

Os rendimentos médios do trabalho na RMRJ, por sua vez, apresentaram desempenho superior ao da RMSP e do Brasil. Entre 2003 e 2013, os rendimentos dos ocupados na RMRJ cresceram 38\%, bastante superior à expansão da RMSP, de 17\% e à do Brasil, de 27\%. Assim, os rendimentos médios dos ocupados na RMRJ (R\$1.939, na média de janeiro a maio de 2013) se aproximaram à da RMSP (R \$ 1.977).

Entretanto, quando se analisa a desigualdade de renda no mercado de trabalho, o quadro é menos favorável. A desigualdade dos rendimentos do trabalho, medida também pelo Coeficiente de Gini, destaca-se como a mais alta entre as RMs brasileiras. Em 2003, o Rio de Janeiro tinha a segunda menor desigualdade, perdendo apenas para Porto Alegre, porém, como teve a menor redução na década, passou a ser a região mais desigual em 2013. O Gráfico 3 mostra que, entre 2003 e 2013, a redução do Coeficiente de Gini na RMRJ foi de $5 \%$, menos da metade da redução na RMSP (13\%). Além disso, a trajetória da desigualdade da renda do trabalho a partir de 2010 tem um descolamento da RMSP, devido à maior redução no Coeficiente de Gini em relação ao Brasil, enquanto a RMRJ se distancia ficando mais desigual do que a média do Brasil Metropolitano.

\footnotetext{
${ }^{8}$ A taxa de participação é calculada pela razão entre a população economicamente ativa (PEA) e a população em idade ativa (PIA).

${ }^{9}$ A menor taxa de participação no mercado de trabalho do Rio de Janeiro ocorre para homens e mulheres e para todas as faixas etárias, principalmente entre os mais jovens.
} 


\section{Gráfico 3}

\section{Coeficiente de Gini do Rendimento do Trabalho}

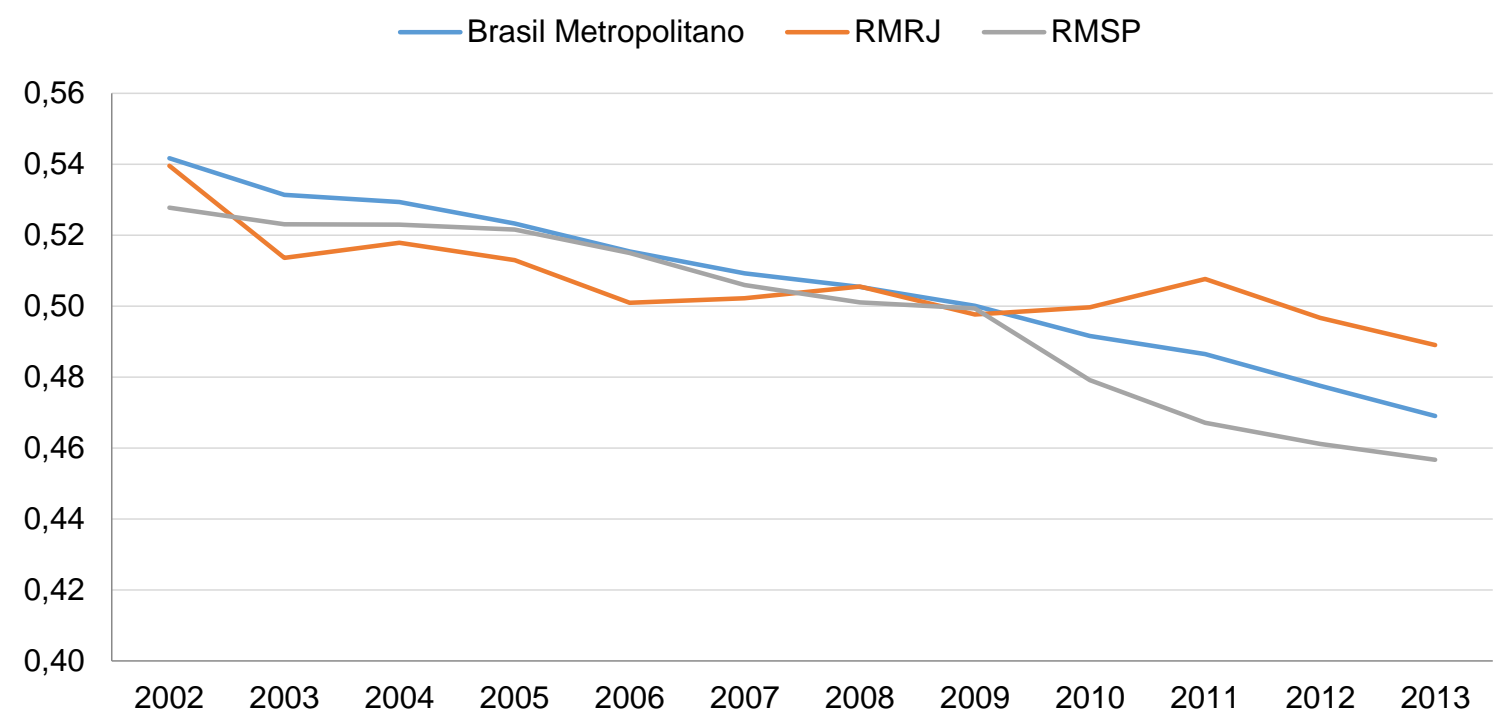

Fonte: PME/IBGE. Nota: Estimativas referentes ao rendimento habitualmente recebido no trabalho principal (média dos 12 meses). Para 2002 foram considerados apenas os meses de março a dezembro e em 2013 os meses de janeiro a maio.

Uma das possíveis explicações para a persistência da desigualdade nos rendimentos do trabalho nos últimos anos reside na trajetória dos diferenciais salariais por nível educacional no Rio de Janeiro. Os diferenciais salariais por nível de instrução registraram queda expressiva no Brasil e na RMSP na última década, propiciando a redução na desigualdade de rendimentos do trabalho. ${ }^{10} \mathrm{Na}$ RMRJ, a diminuição nos retornos à educação só ocorre até o ensino médio. O Gráfico 4 mostra que o diferencial de rendimentos dos ocupados com o ensino superior em relação àqueles com mesmas características, porém com ensino médio, aumenta no Rio de Janeiro, ao contrário do que ocorre na RMSP e no Brasil.

${ }^{10}$ Ver Barros et al. (2007). 


\section{Gráfico 4}

Diferencial salarial $(\%)$ dos ocupados com o ensino superior em relação àqueles com mesmas características, porém com ensino médio completo

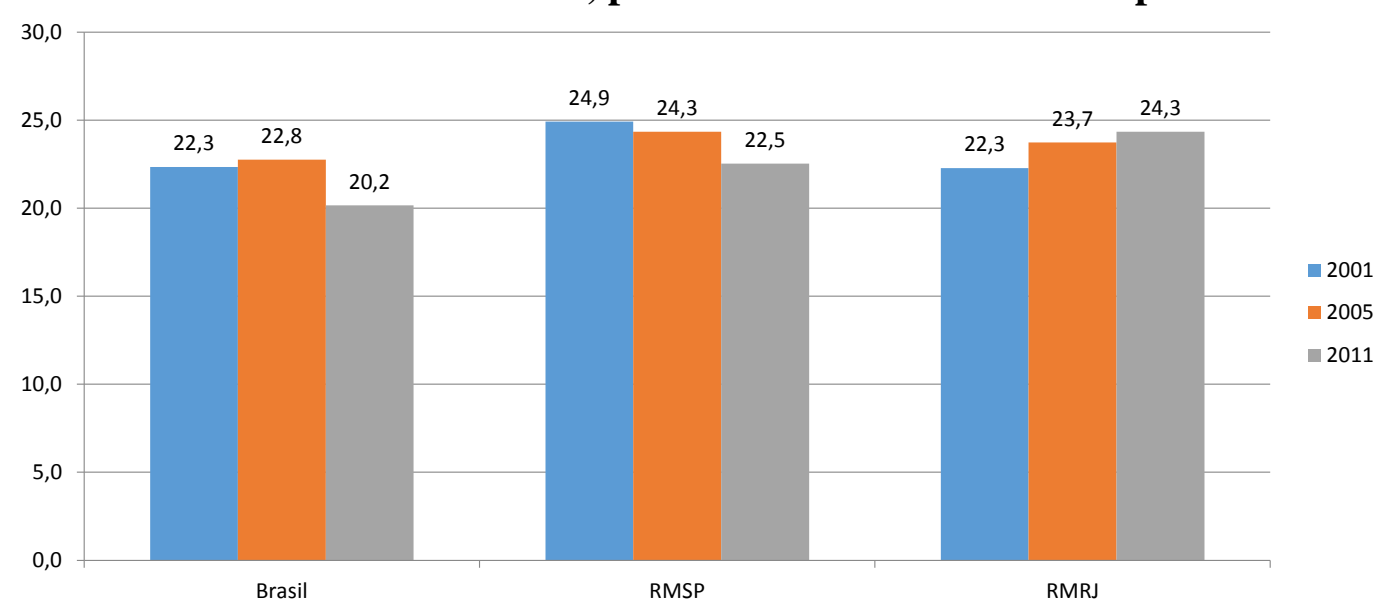

Fonte: IETS a partir de dado da PNAD/IBGE.

Também pode estar contribuindo para a trajetória da desigualdade na RMRJ a natureza do crescimento do Rio de Janeiro, baseada em setores com forte presença de grandes empresas. A participação das micro e pequenas empresas (MPE) no emprego formal e na massa salarial no Rio de Janeiro é bem mais baixa do que a média brasileira (35\% e 22\% na RMRJ contra $42 \%$ e $29 \%$ no Brasil). O diferencial salarial entre os empregados de micro e pequenas empresas (MPE) e de médias e grandes empresas (MGE) na RMRJ é de 97\%, bem maior do que no Brasil e na RMSP (68\%). Entre 2001 e 2011, os diferenciais na RMRJ ficaram praticamente estáveis.

Outro indicador do mercado de trabalho que coloca a RMRJ em situação menos favorável que outras RMs é o de informalidade. Apesar da expansão do percentual de empregados com carteira assinada na última década, que passou de 41\% em 2002 para 49\% dos ocupados em 2013, a RMRJ permanece com um dos menores índices, perdendo apenas para a do Recife $(48,1 \%)$, conforme o Gráfico 5. A RMRJ é a que possui o maior percentual de funcionários públicos, cerca de um a cada dez ocupados. Porém, mesmo somando as duas posições na ocupação, temos um baixo percentual de empregados formalizados no total de ocupados, superior apenas ao de Recife. 


\section{Gráfico 5}

Proporção de empregados com carteira e de funcionários públicos no total de ocupados - 2012

— Funcionários públicos Empregados com carteira

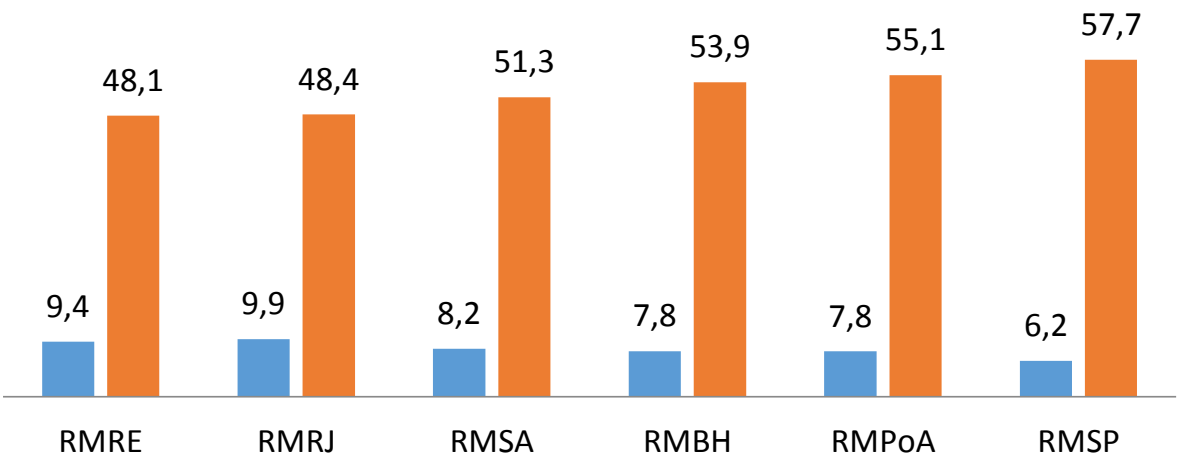

Fonte: IETS, com base na PME/IBGE.

Em contrapartida, a RMRJ tem o mais elevado percentual de trabalhadores por conta própria (21\% dos ocupados, em 2012) das regiões metropolitanas. Já os empregadores representam apenas 4,4\% dos ocupados, percentual superior somente ao das regiões metropolitanas do Nordeste. Com isso, a taxa de sucesso dos empreendedores, medida pela proporção de empregadores no total de empreendedores (conta própria + empregador), na RMRJ é a segunda menor, junto com Recife, de 17,3\%, sendo a maior em Belo Horizonte $(23,4 \%)$.

No tocante ao perfil setorial da ocupação, na comparação com a RMSP e com o Brasil metropolitano, a RMRJ destaca-se principalmente pela maior participação da administração pública e pela menor representatividade dos segmentos industriais (Gráfico 6). De fato, o peso da administração pública é o maior das seis regiões metropolitanas da PME, enquanto a participação da indústria só é mais alta do que na Região Metropolitana de Salvador. Em termos de evolução da composição setorial na última década, destaca-se o crescimento dos serviços (com exceção dos domésticos) e da administração pública e a queda da indústria e do comércio. 


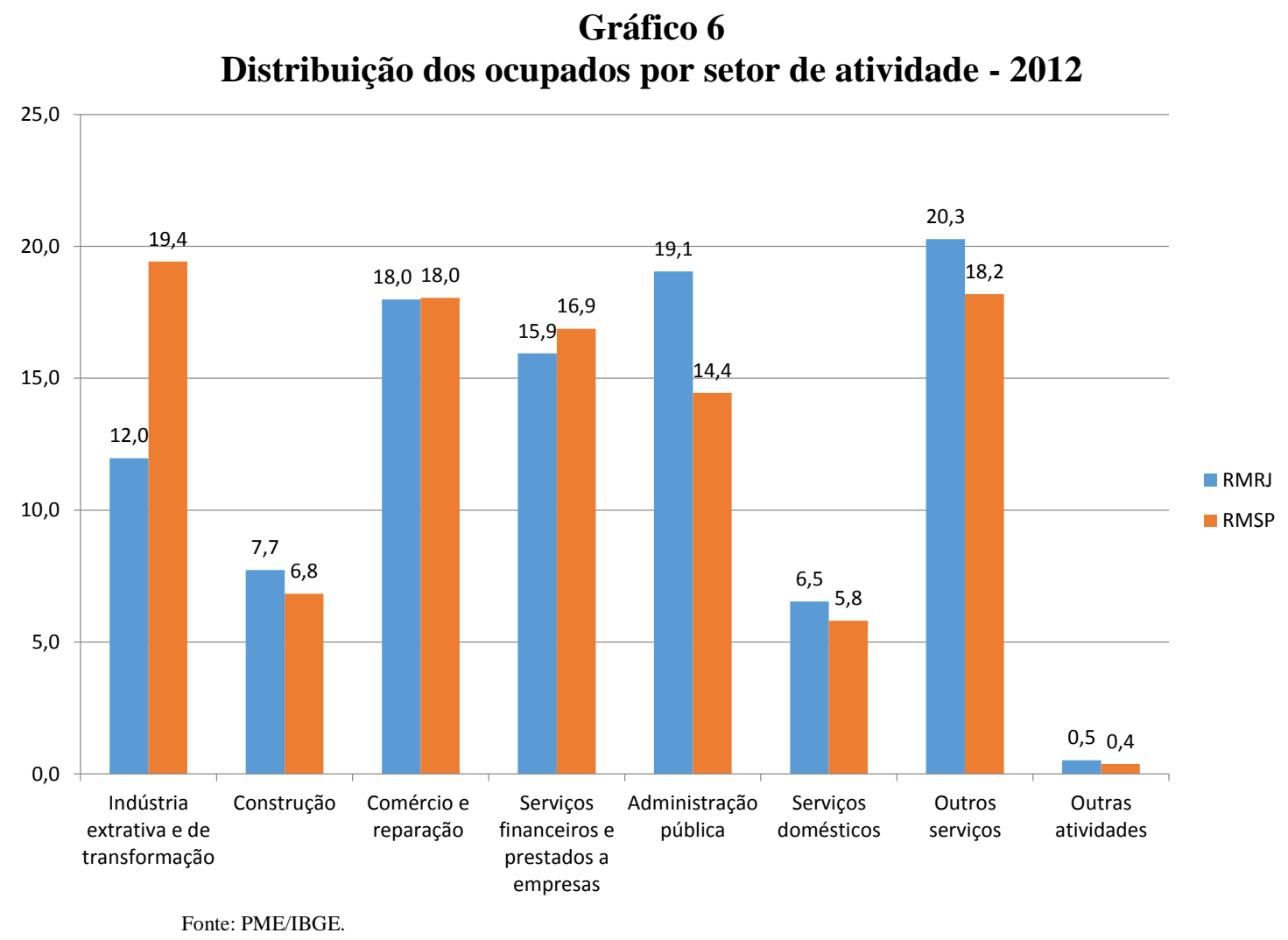

$\mathrm{Na}$ análise dos rendimentos na última década (2002-2012) por setor de atividade, notase crescimento dos rendimentos da administração pública (17\%), intermediação financeira (7\%), indústria (24\%) e construção (39\%). O Gráfico 7 mostra que os serviços domésticos que apresentaram um encolhimento no período em termos de número de ocupados também registraram ganhos de renda de $31 \%$. Já os rendimentos nos outros serviços e no comércio, que ocupam relativamente mais trabalhadores de mais baixa escolaridade, permaneceram estáveis, contribuindo em alguma medida para o ritmo lento de diminuição da desigualdade. 


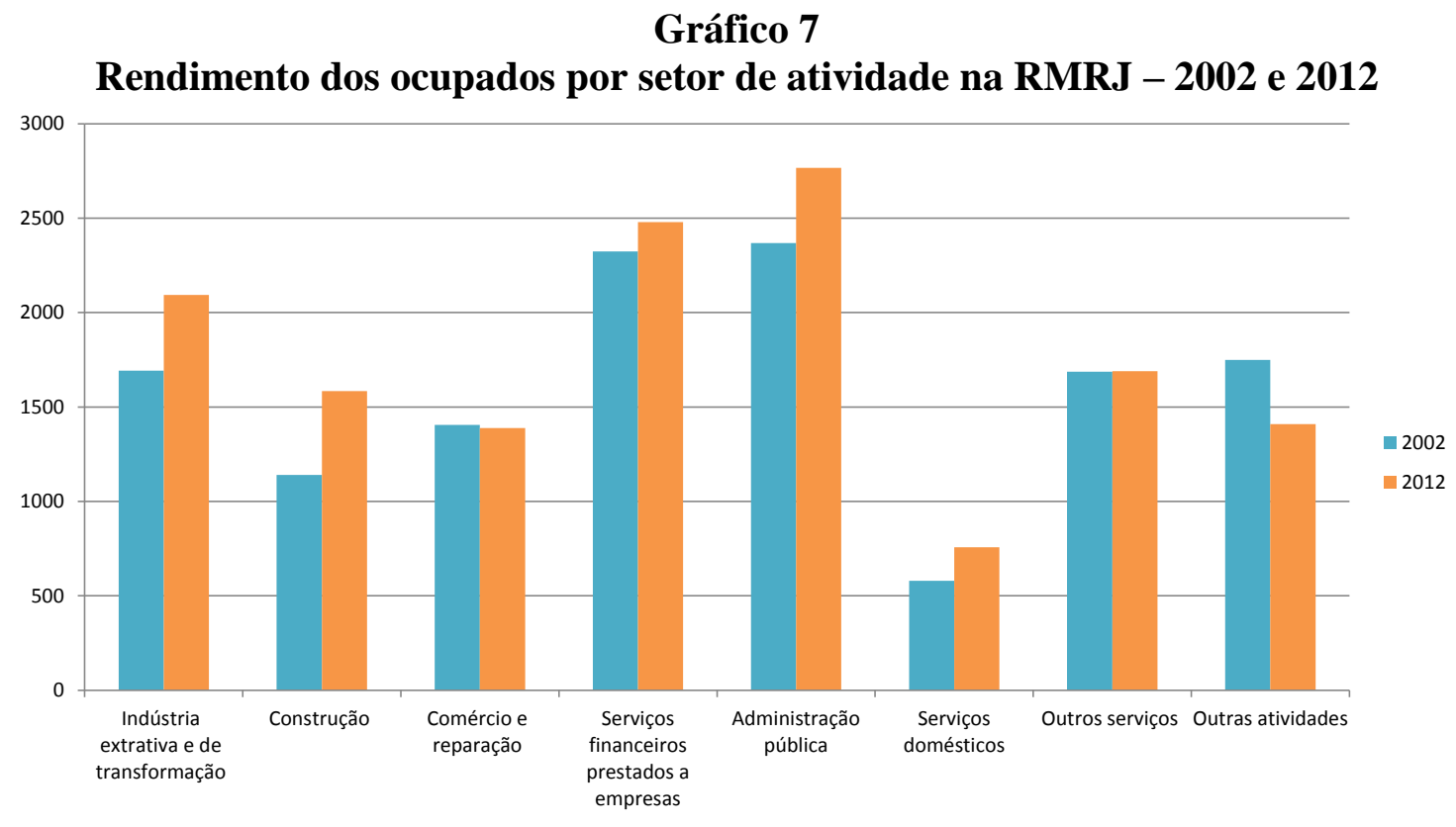

Fonte: PME/IBGE.

Enfim, enquanto no início dos anos 2000, a encrenca metropolitana era das grandes metrópoles do Rio e de São Paulo, em 2011 os problemas da informalidade e da pobreza parecem persistir mais na metrópole fluminense. Isso ocorre em função de um ritmo mais lento na redução da desigualdade de renda, em que a RMRJ vai aos poucos perdendo a sua posição e se descolando da trajetória da média brasileira e da RMSP.

Esta evidência torna ainda mais complexa a busca por soluções dentro do ERJ e seus recortes territoriais (RMRJ, capital, RMRJ sem capital e área não metropolitana), tão díspares em termos de desenvolvimento. Compreender estas especificidades territoriais é fundamental para encontrarmos caminhos rumo a um estado próspero e mais justo e será o foco da próxima seção.

\section{A desigualdade territorilizada: capital e periferia da Região Metropolitana e interior do Estado do Rio de Janeiro}

A análise do crescimento econômico do Estado do Rio de Janeiro pela ótica de seus distintos recortes territoriais - capital, RMRJ sem a capital (periferia) e área não metropolitana (interior) - mostra desempenhos bastante diferenciados. Como pode ser visto no Gráfico 8, de 2002 a 2010, o PIB do Município do Rio de Janeiro cresceu 12,3\%, enquanto 
os demais municípios da RMRJ (exceto a capital) e a área não metropolitana cresceram, respectivamente, $23,4 \%$ e $70,6 \%$ no mesmo período.

\section{Gráfico 8}

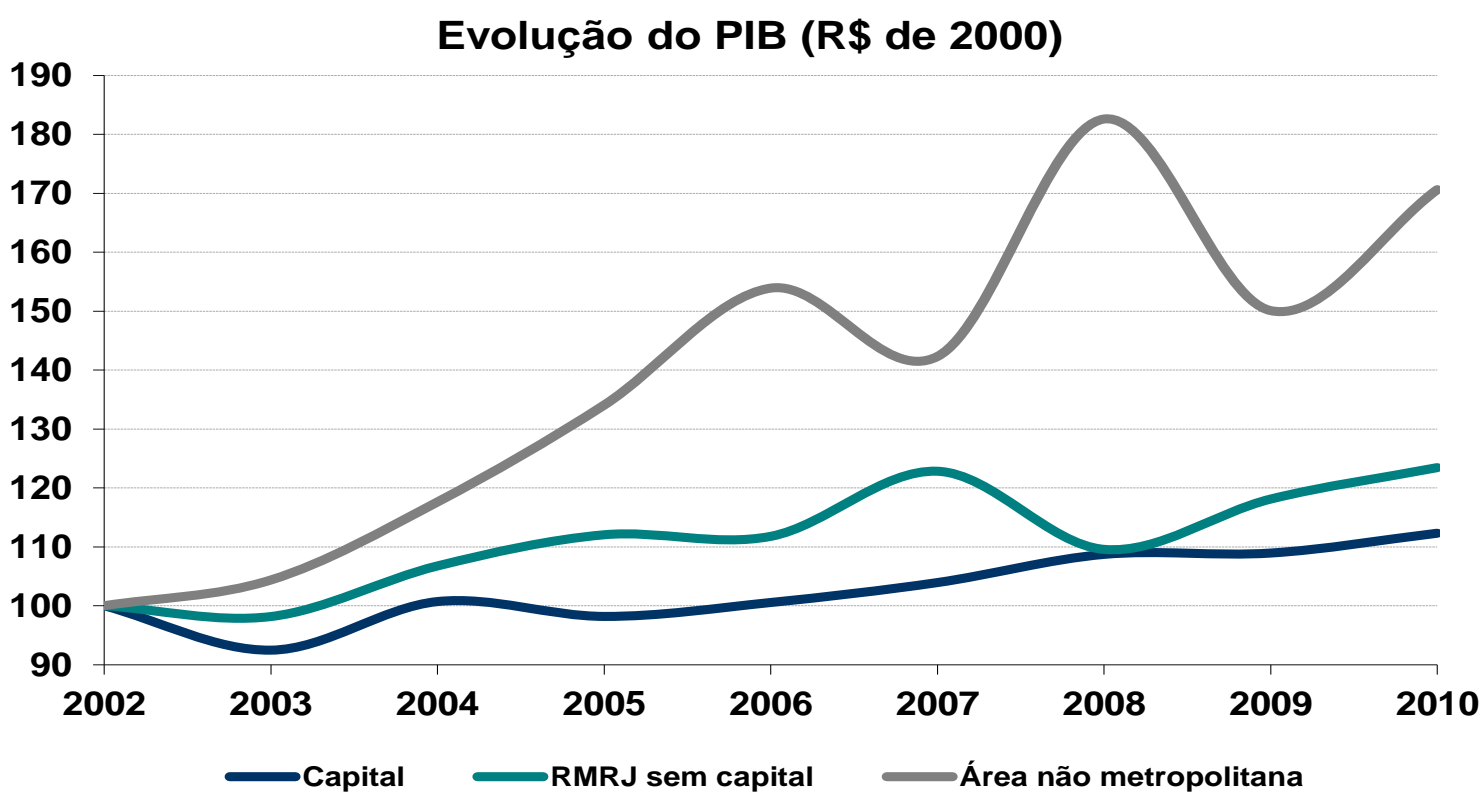

Fonte: IETS com base nos dados do Ipeadata.

A trajetória da atividade econômica na área não metropolitana está relacionada à presença das atividades petrolíferas. O Norte Fluminense apresentou a maior taxa de crescimento no mesmo período, a saber, de $91,3 \%$, entre as seis mesorregiões do estado.

Enquanto a periferia e o Município do Rio de Janeiro têm os serviços como atividade majoritária, com $70 \%$ e $66 \%$ do valor adicionado, a composição setorial do produto é mais equilibrada no interior: entre 2002 e $2009,52 \%$ do PIB adveio da indústria e $39 \%$ do setor de serviços, em média.

\subsection{Renda, pobreza e desigualdade}

No Rio de Janeiro, há uma grande disparidade entre a renda média na capital, na periferia e no interior do estado, como pode ser visto no Gráfico 9. Enquanto a renda domiciliar per capita da capital correspondeu a R\$ 1260 em 2011, bastante acima da 
observada na região Sudeste ( $\mathrm{R} \$ 903)$, a do interior ( $\mathrm{R} \$ 712)$ atinge a da média nacional, de $\mathrm{R} \$ 762$, e a da região metropolitana sem a capital (R\$ 749) fica abaixo.

\section{Gráfico 9}

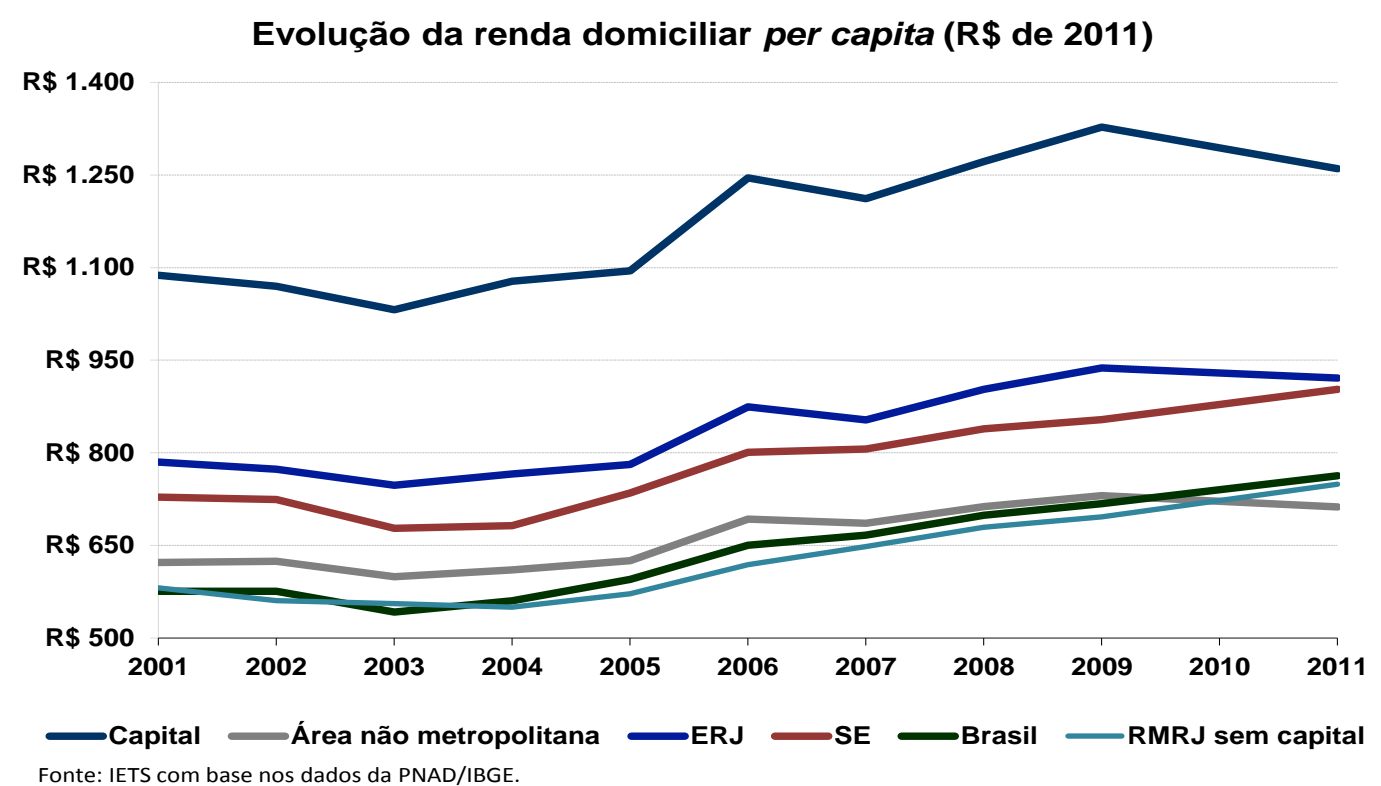

A persistência da desigualdade na região metropolitana se deve sobretudo ao comportamento da capital. Entre 2001 e 2011, o Coeficiente de Gini diminuiu de maneira tímida na cidade do Rio e, mais fortemente, no interior do Estado (Gráfico 10). Desse modo, o interior passou a ser menos desigual do que os municípios da periferia da região metropolitana a partir de 2008.

\section{Gráfico 10}

\section{Evolução do coeficiente de Gini}

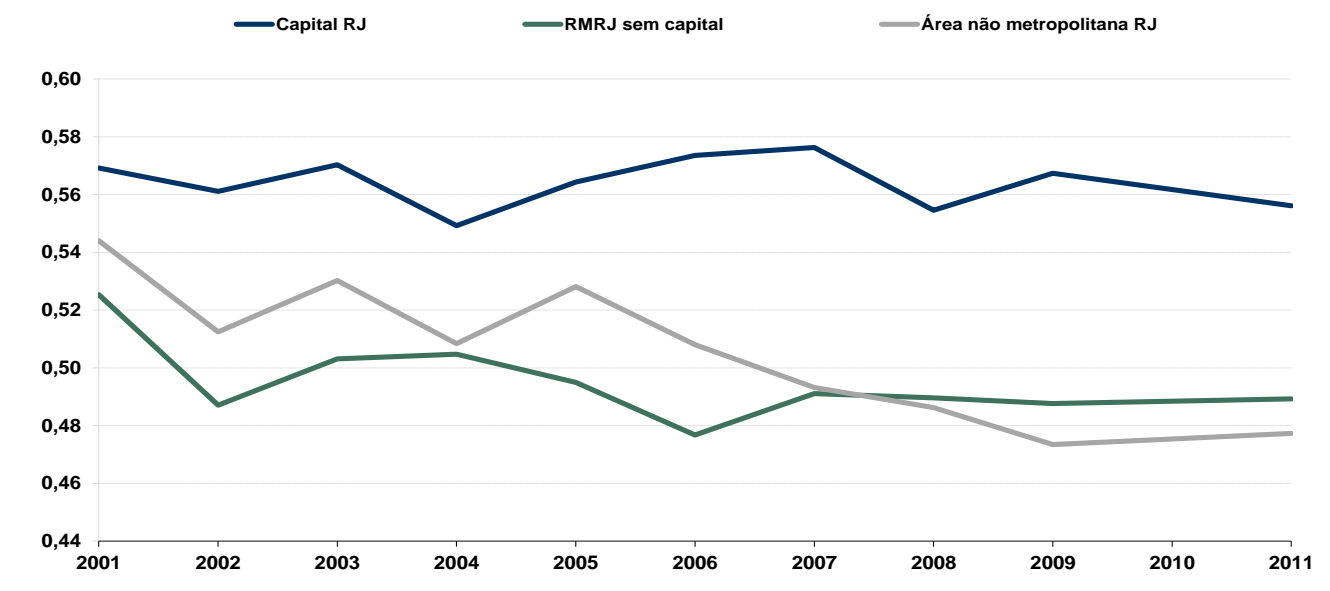


Analisando o período como um todo, verifica-se uma diminuição do percentual de pessoas vivendo abaixo da linha de pobreza, sendo menos intensa na capital do estado. Entre 2009 e 2011, no entanto, o decréscimo da renda conjugado ao aumento da desigualdade levou a um aumento no percentual de pessoas vivendo abaixo da linha de pobreza no interior do estado, assim como na capital. Dessa forma, o Gráfico 11 mostra que a trajetória de queda da pobreza desde 2005 em ambos foi interrompida.

Ainda assim, em 2011, o percentual de pobres no Município do Rio de Janeiro $(13,5 \%)$ é inferior ao da área não metropolitana, de 15\%, e da periferia da RMRJ, que registra maior percentual (19\%). De fato, a periferia da região metropolitana concentrou $44 \%$ dos pobres do Rio de Janeiro em 2011, a capital respondeu por $30 \%$ da pobreza no estado, e o interior, pelos $26 \%$ restantes.

\section{Gráfico 11}

\section{Evolução do percentual de pessoas abaixo da linha de pobreza}

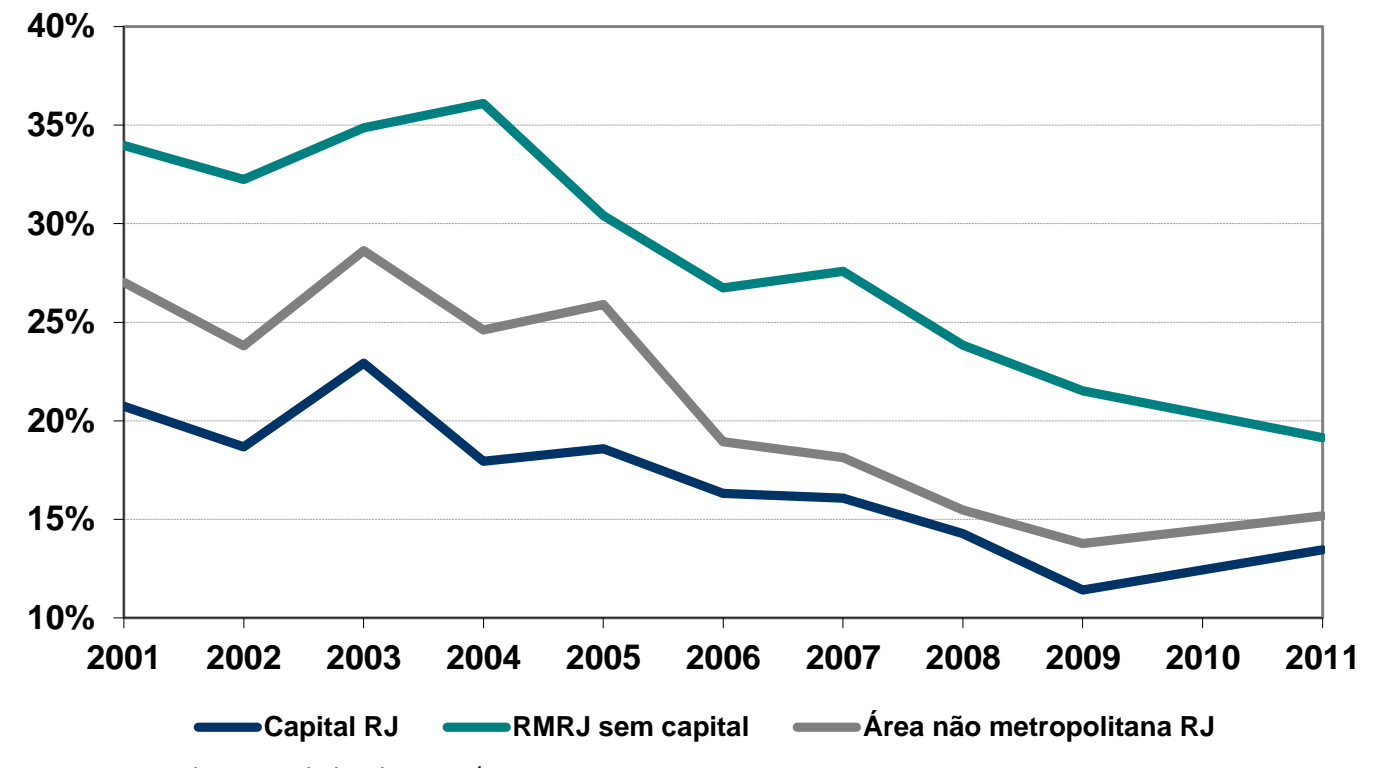

Fonte: IETS com base nos dados da PNAD/IBGE.

Esses indicadores mostram que a capital do Rio, embora ostente uma renda média elevada, tem freado a queda da desigualdade de renda do estado. A diminuição da pobreza também foi mais lenta e, em 2011, o percentual de pobres da cidade se aproximou ao das outras áreas do estado. Apesar da periferia da RMRJ ter diminuído mais a pobreza 
recentemente, ainda registra o índice mais elevado do estado. $\mathrm{Na}$ próxima seção, será investigado como as condições de renda foram afetadas pelas especificidades do mercado de trabalho em cada um dos três recortes territoriais do estado.

\subsection{Mercado de trabalho}

A população economicamente ativa do Estado do Rio de Janeiro segue a distribuição da população: $40 \%$ vivem na cidade do Rio de Janeiro, $34 \%$ na periferia da RMRJ e $26 \%$ no interior. Quase $40 \%$ dos desempregados vivem na periferia da RMRJ, 1/3 deles mora na capital e $27 \%$ são do interior.

A capital e a periferia da Região Metropolitana do Rio de Janeiro possuem taxas de atividade baixas e similares às do estado, de $62 \%$. A taxa de participação é um pouco maior (1 p.p.) no interior, conforme Gráfico 12. A taxa de desemprego da RMRJ (8\%) foi reduzida pela baixa desocupação na capital $(6,7 \%) .{ }^{11} \mathrm{O}$ maior nível de desemprego está na periferia da região metropolitana, $9,7 \%$, seguida do interior com $8,7 \%$.

A tendência de queda do desemprego observada no estado desde 2005 é também verificada no município e na periferia da RMRJ, porém não é observada no interior. Desde 2007, a taxa de desemprego se manteve estável no interior, sendo que, em 2011, sobe levemente. Assim, o interior que tinha um desemprego menor do que a região metropolitana passou a ter proporcionalmente mais desempregados em 2011.

\footnotetext{
${ }^{11}$ A taxa de desemprego na RMRJ aferida pela Pesquisa Mensal do Emprego (PME/IBGE) em 2011 foi de 5,2\% e tem mantido a trajetória de queda iniciada em 2006. Assim, em abril de 2013, chegou a 4,2\%, a segunda menor entre as seis maiores regiões metropolitanas, superior a Porto Alegre. Foi a menor taxa de desocupação de abril desde o início da série em março de 2002.
} 
Tabela 1

Resumo dos indicadores de mercado de trabalho - 2011

\begin{tabular}{lcccc}
\hline & Estado & Interior & Periferia & Capital \\
\hline Taxa de desemprego & $8,2 \%$ & $8,7 \%$ & $\mathbf{9 , 7} \%$ & $6,7 \%$ \\
\hline empregados com carteira & $48,8 \%$ & $44,7 \%$ & $47,9 \%$ & $52,1 \%$ \\
\hline conta própria & $20,9 \%$ & $19,7 \%$ & $\mathbf{2 3 , 3 \%}$ & $19,8 \%$ \\
Taxa de sucesso dos empreendedores & $12,8 \%$ & $12,4 \%$ & $\mathbf{1 0 , 9 \%}$ & $14,7 \%$ \\
\% de conta própria com CNPJ & $15,2 \%$ & $18,2 \%$ & $\mathbf{1 3 , 7 \%}$ & $17,5 \%$ \\
\hline de empregador com CNPJ & $77,2 \%$ & $80,0 \%$ & $\mathbf{7 1 , 5 \%}$ & $83,9 \%$ \\
\hline Remuneração média do trabalho & $\mathrm{R} \$$ & $\mathrm{R} \$ 1.136$ & $\mathbf{R} \$$ & $\mathrm{R} \$ 1.923$ \\
\hline
\end{tabular}

Fonte: IETS, com base nos dados da PNAD/IBGE.

No que se refere à posição na ocupação, houve aumento generalizado da proporção de empregados com carteira de trabalho assinada, porém é consideravelmente mais baixa na área não metropolitana do Rio de Janeiro. Apenas 45\% dos ocupados são empregados formais no interior; já na periferia da RMRJ e na capital, respectivamente $48 \%$ e $52 \%$ dos trabalhadores possuíam carteira assinada em 2011.

De forma complementar, a participação do emprego sem carteira diminuiu na capital, periferia e no interior na última década. Em outras palavras, $21 \%$ dos empregados na área não metropolitana são informais, enquanto na periferia representam $18 \%$ dos empregados e na capital, $15 \%$.

O percentual de funcionários públicos entre os ocupados, por sua vez, mostrou maior expansão de 2001 a 2011 (1,6 p.p.) e maior nível (9,3\%) neste último ano no interior do ERJ. A capital mostrou estabilidade neste percentual, em 8,6\%, enquanto a periferia da RMRJ atingiu $6,3 \%$.

Assim como no estado como um todo, entre 2001 e 2011 houve diminuição da participação dos empreendedores na ocupação total, tanto dos trabalhadores por conta própria quanto dos empregadores. Em termos de composição, os trabalhadores por conta própria têm participação mais elevada na periferia (23\%) e os empregadores na capital $(3,4 \%)$. A menor taxa de sucesso dos empreendedores está na periferia da região metropolitana, onde somente 
$10,9 \%$ dos empreendedores são empregadores. ${ }^{12}$ Esse percentual correspondeu a $12,4 \%$ no interior e $14,7 \%$ na capital.

Em relação à composição setorial do emprego, observa-se um padrão semelhante à do produto: enquanto mais da metade dos ocupados na capital $(60 \%)$ e na periferia $(51 \%)$ da RMRJ se concentram no setor de serviços, no interior do estado esse percentual é de $46 \%$. Por outro lado, enquanto na capital a indústria e construção civil não representam sequer $10 \%$ da ocupação total individualmente, no interior e na periferia respectivamente $13 \%$ e $11 \%$ dos trabalhadores estão alocados no primeiro e $12 \%$ no segundo em ambas localidades.

Assim como a renda domiciliar per capita, a remuneração média do trabalho na capital $(\mathrm{R} \$ 1.924)$ é superior à na periferia ( $\mathrm{R} \$ 1.247)$, que por sua vez é mais alta do que a observada no interior, de $\mathrm{R} \$ 1.136$. Embora o interior tenha apresentado o maior crescimento anual da renda do trabalho ao longo da década, entre 2009 e 2011, os rendimentos variaram menos no interior do que no Rio de Janeiro como um todo. Consequentemente, a remuneração dos trabalhadores no interior do estado ficou abaixo da média brasileira.

A amplitude da desigualdade - em se tratando do diferencial salarial por nível de escolaridade - é superior no ERJ em relação ao Sudeste e ao Brasil, e tão maior quanto mais próximo à capital fluminense. O retorno salarial aumenta com escolaridade e é maior na capital do que na periferia e no interior, conforme mostra a tabela a seguir.

\section{Tabela 2}

Diferencial salarial da população ocupada de 25 anos e mais por nível educacional

\begin{tabular}{|c|c|c|c|c|c|c|c|c|}
\hline Nivel educacional & Brasil & Sudeste & $\begin{array}{c}\text { São Paulo } \\
\text { Metropolitano }\end{array}$ & Rio de Janeiro & $\begin{array}{l}\text { Rio de Janeiro } \\
\text { Metropolitano }\end{array}$ & $\begin{array}{l}\text { Rio de Janeiro } \\
\text { Interior }\end{array}$ & $\begin{array}{l}\text { Rio de Janeiro } \\
\text { Capital }\end{array}$ & $\begin{array}{l}\text { Rio de Janeiro } \\
\text { Periferia }\end{array}$ \\
\hline Diferencial médio & 8,3 & 6,1 & 5,5 & 5,5 & 5,1 & 6,0 & 5,7 & 4,0 \\
\hline \multicolumn{9}{|l|}{ Diferencial por nível } \\
\hline $1^{\circ}$ ciclo do fundamental & 8,2 & 2,7 & 0,3 & 0,3 & $-1,5$ & 4,2 & $-2,3$ & $-0,6$ \\
\hline 2o ciclo do fundamental & 5,5 & 5,1 & 5,4 & 5,0 & 5,2 & 4,0 & 5,6 & 4,3 \\
\hline Ensino Médio & 8,7 & 9,3 & 7,7 & 10,7 & 11,1 & 9,4 & 11,9 & 10,1 \\
\hline Ensino Superior & 20,2 & 19,9 & 22,5 & 23,1 & 24,3 & 18,0 & 26,1 & 18,9 \\
\hline
\end{tabular}

\footnotetext{
${ }^{12}$ Além do menor percentual de empregadores entre os empreendedores, a periferia da RMRJ tem uma baixa taxa de formalização, definida pelo percentual de trabalhadores por conta própria e empregadores com CNPJ.
} 
Por fim, a análise por porte de estabelecimento na geração de trabalho e renda. A participação das micro e pequenas empresas (MPE) ${ }^{13}$ no emprego formal e na massa salarial caiu nos três recortes analisados entre 2001 e 2011, representando um aprofundamento no modelo de desenvolvimento baseado em grandes empresas, capitaneado pelo Município do Rio de Janeiro. Desde 2001, como pode ser visto no Gráfico 12, a capital possui o menor peso de MPE nos empregos formais e na massa salarial, equivalentes a $37 \%$ e $20 \%$ em 2011, respectivamente - o último abaixo da média nordestina, inclusive.

\section{Gráfico 12}

\section{Participação das MPE no emprego formal e na massa salarial}

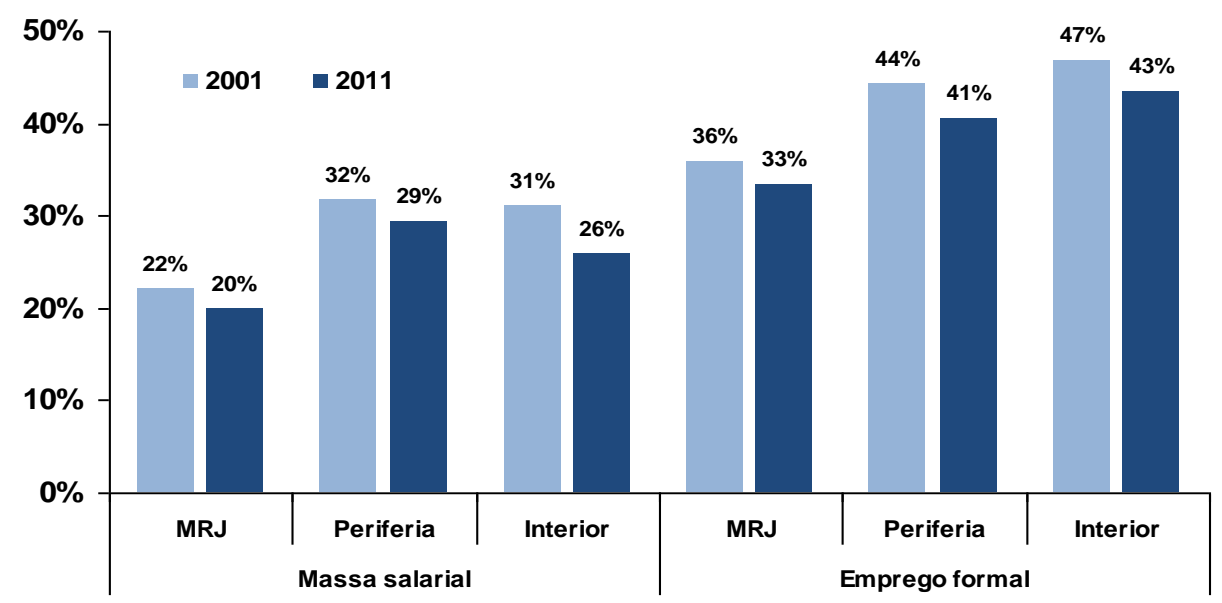

Fonte: IETS com base nos dados da RAIS/MTE.

Entre os empregados formais, o salário médio do Município do Rio de Janeiro ( $\mathrm{R} \$ 2.460)$ é superior ao da região metropolitana ( $\mathrm{R} \$ 2.237)$, onde é mais alto do que no interior do Rio de Janeiro ( $\mathrm{R} \$ 2.001)$. No entanto, o salário médio dos empregados formais na periferia ( $\mathrm{R}$ \$ 1.545) é ultrapassado pelo do interior, como observado em relação à renda do trabalho dos empreendedores (Gráfico 13). Isso ocorre porque os salários da MPE e sobretudo das MGE da área não metropolitana são superiores aos da RM sem a capital. Os menores salários entre os recortes analisados estão entre as MPE da periferia, indicando um problema de baixa produtividade.

\footnotetext{
${ }^{13} \mathrm{O}$ porte ou tamanho de empresas foi definido pelo critério de classificação por número de funcionários, utilizada pelo Sistema SEBRAE. Assim, as micro e pequenas empresas (MPE) compreendem indústrias (de transformação e extrativa mineral) com até 99 funcionários e as empresas agropecuárias, empresas do comércio e empresas dos serviços com até 49 funcionários. Já as médias e grandes empresas (MGE) são indústrias com 100 ou mais funcionários e empresas agropecuárias, do comércio e do serviço com 50 ou mais funcionários.
} 


\section{Gráfico 13}

Salário médio (R\$/empregado) para os recortes do ERJ - 2011

-Salário médio - MPE $\quad$ Salário médio - MGE

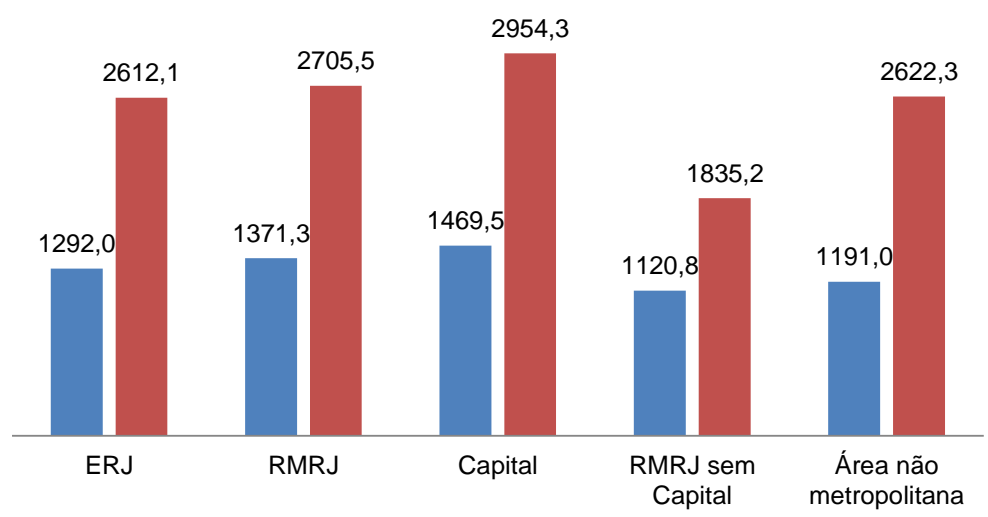

Fonte: Dados extraídos da Relação Anual de Informações Sociais (RAIS), 2001 e 2011

Entre 2001 e 2011 houve expressivo crescimento do salário no interior do ERJ, de mais de $40 \%$. Ao mesmo tempo, a remuneração dos empregados formais aumentou $15 \%$ na capital e $18 \%$ nos municípios da periferia da região metropolitana. Apesar da elevação do salário médio nas MPE no interior (27\%) também ter sido acima da verificada nos demais recortes territoriais, foi o aumento no salário nas médias e grandes empresas, de $42 \%$, que levou a tamanho crescimento.

Por conta disso, o diferencial salarial entre as MPE e MGE no interior subiu de $96 \%$ em 2001 para $120 \%$ em 2011. Esse diferencial é superior ao observado na capital (101\%), que se manteve no patamar de 2001, e na periferia da RMRJ (64\%), onde a distância entre o salário nas MPE e MGE diminuiu 7 p.p. na década.

\section{Considerações finais}

O Estado do Rio de Janeiro tem avançado mais lentamente do que a média brasileira e do que seus vizinhos do Sudeste em vários indicadores socioeconômicos. O presente artigo mostra que este desempenho se deve em grande medida à evolução da sua região metropolitana, que tem sido aquém de outras metrópoles e do Brasil.

Os avanços no combate à pobreza foram menores do que na RMSP e do que na média nacional devido, em alguma medida, à diminuição mais lenta da desigualdade de renda na RMRJ. Entre 2001 e 2011, a queda da desigualdade na RMRJ foi menos da metade da RMSP 
e brasileira, sugerindo que a "encrenca" metropolitana da desigualdade agora é mais fluminense.

Esse desempenho está relacionado, em alguma medida, às características estruturais do mercado de trabalho do Rio de Janeiro. A perda da sua posição de centro industrial para São Paulo, aliada ao fato de ter sido a capital do Brasil durante 150 anos e, portanto, o centro político-administrativo, financeiro, comercial, geraram uma progressiva importância e dependência do setor terciário, com elevada participação da administração pública e baixa representatividade da indústria. Ainda grande parte da estrutura da ocupação é composta por comércio e serviços de mais baixa qualidade e com elevada informalidade.

O modelo de crescimento econômico recente, ancorado em setores com forte presença de grandes empresas, destacando-se a importância da indústria extrativa mineral, não foi capaz de alterar significativamente essas características, em que pesem os investimentos industriais em curso no estado.

O baixo desemprego é influenciado pela baixa taxa de participação no mercado de trabalho e pela elevada informalidade. Apesar do aumento do percentual de empregados com carteira de trabalho assinada, a RMRJ permanece com um dos menores índices de formalização do emprego, perdendo apenas para a do Recife. Seguimos sendo a capital dos trabalhadores por conta-própria e com um percentual baixo de empreendedores que apresentam boa performance e que conseguem gerar empregos.

Os rendimentos do trabalho têm crescido acima da média nacional e de São Paulo, porém a desigualdade dos rendimentos do trabalho é a maior das regiões metropolitanas.

Destacamos duas possíveis explicações para a redução mais lenta da desigualdade na RMRJ. A primeira diz respeito aos diferenciais de rendimento entre quem tem e quem não tem nível superior. Enquanto no Brasil e na RMSP há diminuição nos diferenciais, na RMRJ há aumento. A segunda explicação reside na distância entre os rendimentos dos empregados em MPE e MGE maior na RMRJ do que na média brasileira ou na RMSP.

Isso se deve, sobretudo, ao que ocorre na capital. A capital representa $40 \%$ da população e tem ainda maior peso em termos econômicos: metade do produto e das empresas e $57 \%$ dos empregos formais. Líder em desigualdade, medida pelo Coeficiente de Gini da renda domiciliar per capita, entre as três áreas do estado, a capital também registra o maior diferencial salarial para níveis superiores de escolaridade. 
A periferia da região metropolitana abriga $40 \%$ dos desempregados. É nela também que se concentram os piores indicadores de pobreza e onde moram $44 \%$ das pessoas do ERJ vivendo abaixo da linha de pobreza. Periferia e, principalmente, a capital não foram capazes de reduzir a alta desigualdade de renda na última década, como o interior.

A área não metropolitana do estado tem a menor renda domiciliar per capita, porém, dada a grande redução na desigualdade de renda na última década, passou a registrar índices de pobreza mais baixos do que a região metropolitana. Foi também a região que mostrou maior crescimento do PIB, impulsionado pela economia do petróleo.

Para o Estado do Rio de Janeiro avançar mais rapidamente no seu desenvolvimento precisa encontrar soluções para a sua região metropolitana, que tem freado a redução da desigualdade de renda. $\mathrm{O}$ enfrentamento dos problemas da metrópole na sua complexidade requer visão estratégica para a região metropolitana, coordenação das agendas dos diferentes atores e integração das políticas voltadas, principalmente, para diminuir as desigualdades de oportunidades entre as regiões do estado.

A perda de posição da Região Metropolitana do Rio de Janeiro deve servir de alerta e senso de urgência para a construção de uma agenda estratégica e integrada que enfrente a imensa desigualdade entre distintos territórios do Estado do Rio de Janeiro. Para que este esforço tenha êxito, faz-se necessário inovar na maneira de pensar as políticas públicas, tanto em termos de suas escalas, quanto de seus prazos e governanças. Esta tarefa dificilmente terá êxito sem a união de esforços por parte de atores públicos e privados, bem como da sociedade civil, na busca por soluções que tornem qualquer lugar do estado um local bom para se viver e trabalhar.

\section{Referências bibliográficas}

BARROS, R. et al. (2007). A queda recente da desigualdade de renda no Brasil. In: Desigualdade de Renda no Brasil: uma análise da queda recente (volume 1), Ricardo Paes de Barros, Miguel Nathan Foguel, Gabriel Ulyssea (orgs), IPEA, Brasília.

BARROS, R. P.; FOGUEL, M. N.; ULYSSEA, G. (Orgs.). Desigualdade de renda no Brasil: uma análise da queda recente. Brasília: Ipea, vol. 2, 2007. pp. 17-40.

BARROS, Ricardo Paes e PERO, Valéria. Pobreza no Rio de Janeiro: tendências recentes e desafios para o futuro. In: URANI, André e GIAMBIAGI, Fabio (orgs.). Rio: A Hora da Virada. Editora Elsevier/Campus, 2011. 
CASTELAR PINHEIRO, A; VELOSO. Fernando (Org.). Rio de Janeiro Um estado em transição. 1ed. Rio de Janeiro: FGV, 2012, v. 1, p. 205-230.

OSORIO, M. Características e evolução recente do emprego e da economia carioca e metropolitana. Coleção Estudos Cariocas. Rio de Janeiro: IPP, n.2423, 2011.

PEREIRA, R. \& SCHWANEN, T. - Tempo de deslocamento casa-trabalho no Brasil (19922009): diferenças entre regiões metropolitanas, níveis de renda e sexo. Texto para discussão 1813, IPEA - Brasília, 2013.

RAIA JUNIOR, A. - Mobilidade e Acessibilidade Urbanas Sustentáveis: A Gestão da Mobilidade no Brasil - UFSCar, São Carlos, SP, 2009.

SOBRAL, B. A Falácia da "inflexão econômica positiva": algumas características da desindustrialização fluminense e do "vazio produtivo" em sua periferia metropolitana. Cadernos do Desenvolvimento Fluminense, Rio de Janeiro, n. 1, fev. 2013.

URANI, A.; GIAMBIAGI, F. Rio: a hora da virada. Rio de Janeiro: Elsevier. 2011. Páginas 191-212.

URANI, A. Trilhas para o Rio. Do reconhecimento da queda à reinvenção do futuro. Campus/Elsevier, 2008. 